\title{
The Rate of Awareness for Familial Mediterranean Fever for Urban Dwellers in Turkey
}

\author{
Türkiye'nin bir Metropolünde Yaşayan Halkın Ailevi Akdeniz Ateşi Farkındalığı
}

Alper SOYLU, Mehmet Atilla TÜRKMEN, Salih KAVUKÇU

Department of Pediatrics, Medical Faculty of Dokuz Eylül University, İzmir, Turkey

The estimated prevalence of familial Mediterranean fever (FMF) in Turkey is $1 / 1000$, and the carrier rate is $1: 5 .{ }^{[1,2]}$ Hence, with a population of more than 67 million inhabitants, a large proportion of all the FMF cases in the world are found in Turkey. ${ }^{[3]}$

In addition, a dramatic decrease in secondary amyloidosis, the most serious complication of FMF, has been reported in Turkey in recent years. This can be attributed to the increased awareness of physicians with regard to FMF. ${ }^{[4]}$ Familial Mediterranean fever was highlighted as a health problem due in large part to a study published in 1993 that reported on this disorder in Turkey. ${ }^{[5]}$ In 1998, the high prevalence rate of FMF at $1 / 1.073$ in a field study placed it as one of the most frequent genetic diseases in Turkey. ${ }^{[6]}$ Subsequently, there have been increased efforts to train Turkish physicians regarding this inherited disorder. In 2005, a nationwide study on FMF further increased awareness and verified the need for healthcare professionals to become more familiar with it. ${ }^{[3]}$ The main factor for the dramatic decrease in the cases of renal amyloidosis in Turkey is thought to be due to better medical education and practice among Turkish physicians which has led to the increased use of colchicine. ${ }^{[4]}$

Unfortunately, only the education of physicians is not enough to prevent complications due to FMF. The general population should also be educated for the signs and symptoms of this frequent genetic disease.
The risk of amyloidosis increases if the diagnosis is delayed along with the late implementation of colchicine treatment. In this respect, a mild clinical presentation may be misleading as FMF patients may have "subclinical" inflammation during the attackfree intervals ${ }^{[7]}$ Additionally, a positive family history of amyloidosis has been reported to be an important risk factor for the development of this disease in Turkey (odds ratio, 4.54). ${ }^{[3]}$ Given the high rate of consanguinity among FMF patients in this country $(24 \%),{ }^{[3]}$ the risk of marriage within amyloidosis-prone families is significantly higher.

We aimed to determine the awareness of FMF among the people living in Izmir, the third largest city in Turkey. A cross-sectional study was planned among the people visiting the mega shopping centers in this metropolis. The study was designed as a working module for students to not only improve their ability in the use of face-to-face questionnaires, but to increase general awareness of FMF as a health problem. This study could not be regarded as an epidemiological study since no sampling method was used prior to the questionnaire. However, we assumed that mega shopping centers would have visitors from all socioeconomic levels. The minimum number of people representing the study population was calculated as 384 with 95\% confidence level (CI) based on the population of İzmir at 3,965,232 in 2011 according to the Turkish Statistical Institute. ${ }^{[8]}$ This assumed

\footnotetext{
Received: April 17, 2012 Accepted: July 9, 2012

Correspondence: Alper Soylu, M.D. Dokuz Eylül Üniversitesi Tıp Fakültesi Çocuk Sağlığı ve Hastalıkları Anabilim Dalı, 35210 Alsancak, İzmir, Turkey.

Tel: +90 232 - 4126197 e-mail: alper.soylu@deu.edu.tr

Presented at the $1^{\text {st }}$ PUADER Congress, 23-27 April 2012, Antalya, Turkey

(C2012 Turkish League Against Rheumatism. All rights reserved.
} 
a 50\% expected frequency and 5\% worst acceptable error. A questionnaire was used to gather information regarding FMF, and visitors to mega shopping centers were asked to fill out these questionnaires on working days from 6-7 pm during the month of May in 2011. Those who were over 15 years of age and who gave verbal consent were enrolled in the study. However, participants who were medical doctors were excluded. Statistical analysis was carried out using the Statistical Package for the Social Sciences (SPSS, Inc., Chicago, Illinois USA) version 15.0 for Windows using a chisquare test. A $p$ value of $<0.05$ was considered to be significant.

The number of people who responded to the survey was 524 (mean age $33.4 \pm 13.1$ years; range 16 to 74 years). There were 267 males ( $51 \%$; mean age $35.0 \pm 13.8$ years) and 257 females (49\%; mean age 31.9 \pm 12.0 years). Participants who answered affirmatively to the question, "Have you ever heard about familial Mediterranean fever?" were considered to be informed $(n=99,18.9 \%)$ while the rest were considered to be uninformed (81.1\%). None of the informed participants were FMF patients. The statistical rate at which participants were informed was not affected by gender or place of birth. In addition, having a family member who was a doctor also had no effect. However, we discovered that students were more informed (35.3\%).

Among the informed participants, $78 \%$ considered the role of consanguinity in FMF to be important. Their complaints with regard to FMF were as follows: fever (84\%), joint pain (54\%), abdominal pain (47\%), myalgia (37\%), and chest pain (25\%). They also denoted the specific consequences of FMF as follows: renal failure (56\%), female infertility (42\%), male infertility (28\%), liver failure (27\%), and heart failure (26\%). Moreover, $72 \%$ of the informed participants reported that treatment existed for FMF; however, only $12 \%$ could name colchicine as the drug that is primarily used. The factors triggering an FMF attack according to the informed participants were sleeplessness (56\%), tiredness (61\%), stress (69\%), infections (63\%), and noncompliance with treatment (81\%).

The questionnaire revealed that $26 \%$ of the participants had a family member with FMF who served as their source of information, $20 \%$ reported that their source was personal contact with friends, neighbors, etc., $15 \%$ cited that it was television or newspapers, $30 \%$ said that it was the internet, and $8 \%$ responded that their source of information regarding FMF was medical staff.
The decreased rate of amyloidosis secondary to FMF in Turkey in recent years has been attributed to the increased awareness of physicians about FMF. ${ }^{[4]}$ However, to our knowledge, there is no study that has evaluated the awareness of Turkish people in general regarding FMF. We presumed that the information status of a given population concerning a frequent disease like FMF would affect the early diagnosis and adequate treatment. In fact, in a study performed in Israel to identify the factors that had contributed to a more than 10-year delay in the diagnosis of FMF, the cause was found to stem from misdiagnosis and physician negligence $(70 \%)$ as well as patient negligence $(70 \%)$. That study demonstrated that unexpected causes, such as social status (immigrants), female gender, physician negligence, and lack of patient awareness, were behind the prolonged delay in the diagnosis of FMF. ${ }^{[9]}$ The results of our preliminary study showed that less than one-fifth of the population in Izmir was aware of the existence of this frequent genetic disease. This may lead to the low rate in obtaining medical care which led to underdiagnosis or late diagnosis of FMF, especially in patients with milder symptoms. However, it has been reported that the severity of the disease course and development of amyloidosis may not be uniformly concordant. ${ }^{[3]}$ Thus, a lack of awareness of a population for FMF would lead to an increased rate of secondary amyloidosis.

A nationwide study concerning FMF demonstrated that patients with FMF originate mainly from the non-Mediterranean regions of Turkey. When the parental origins were considered, over $70 \%$ of the reported cases came from central and eastern Anatolia and the inner Black Sea regions. ${ }^{[3]}$ We aimed to see if participants from those regions (29\% of all study population, reflecting the intense migration of people from eastern to western Turkey) were more aware of FMF than other areas. However, the rate of awareness with respect to FMF did not differ between regions.

The source of information for most of the participants was non-experts (friends, neighbors, relatives, television, etc.). This implies there is insufficient formal training for the Turkish population regarding FMF. The higher awareness of students may be associated with the high rate of internet use in this group of participants.

In conclusion, less than $20 \%$ of the population in the third largest city in Turkey was aware of FMF. 
Furthermore, most of those who had heard about FMF obtained this knowledge via informal sources, such as from their neighbors. Awareness is highest among students who use the internet more frequently and efficiently. Although this study was performed on a limited sample of the population, the results indicate that formal education of the community about FMF should be undertaken in order for the timely presentation and effective treatment of patients with this disease.

\section{Declaration of conflicting interests}

The authors declared no conflicts of interest with respect to the authorship and/or publication of this article.

\section{Funding}

The authors received no financial support for the research and/or authorship of this article.

\section{REFERENCES}

1. Dinc A, Pay S, Turan M, Simsek I. Prevalence of familial Mediterranean fever in young Turkish men. Clin Exp Rheumatol 2000;18:292.
2. Yilmaz E, Ozen S, Balci B, Duzova A, Topaloglu R, Besbas $\mathrm{N}$, et al. Mutation frequency of Familial Mediterranean Fever and evidence for a high carrier rate in the Turkish population. Eur J Hum Genet 2001;9:553-5.

3. Tunca M, Akar S, Onen F, Ozdogan H, Kasapcopur O, Yalcinkaya F, et al. Familial Mediterranean fever (FMF) in Turkey: results of a nationwide multicenter study. Medicine (Baltimore) 2005;84:1-11.

4. Akse-Onal V, Sağ E, Ozen S, Bakkaloglu A, Cakar $\mathrm{N}$, Besbas $\mathrm{N}$, et al. Decrease in the rate of secondary amyloidosis in Turkish children with FMF: are we doing better? Eur J Pediatr 2010;169:971-4.

5. Saatci U, Bakkaloglu A, Ozen S, Besbas N. Familial Mediterranean fever and amyloidosis in children. Acta Paediatr 1993;82:705-6.

6. Ozen S, Karaaslan Y, Ozdemir O, Saatci U, Bakkaloglu A, Koroglu E, et al. Prevalence of juvenile chronic arthritis and familial Mediterranean fever in Turkey: a field study. J Rheumatol 1998;25:2445-9.

7. Tunca M, Kirkali G, Soytürk M, Akar S, Pepys MB, Hawkins PN. Acute phase response and evolution of familial Mediterranean fever. Lancet 1999;353:1415.

8. Available from: http://www.turkstat.gov.tr

9. Lidar M, Tokov I, Chetrit A, Zaks N, Langevitz P, Livneh A. Diagnosis delay in familial Mediterranean fever (FMF): social and gender gaps disclosed. Clin Exp Rheumatol 2005;23:357-63. 